\title{
Identification of Influencing Variables of Demand-oriented Measures for Volume Flexibility
}

\author{
Maurice Schmidt", Peter Nyhuis \\ Institute of Production Systems and Logistics, Leibniz University Hannover, Germany
}

Copyright $\bigcirc 2016$ by authors, all rights reserved. Authors agree that this article remains permanently open access under the terms of the Creative Commons Attribution License 4.0 International License

\begin{abstract}
The appropriate response to fluctuating demand situations is a major challenge manufacturing companies currently have to face these days. In particular, the selection of appropriate measures to adapt the production system efficiently is difficult. In order to handle an expected demand fluctuation, the goal is to reply the question about the optimal adjustment time of production systems in combination with measures of capacity synchronization. By the identification of influencing variables this optimum can be found for individual measures as well as for measure combinations. With the help of dynamic capacity envelopes, a pragmatic visualization is provided as well.
\end{abstract}

Keywords Fluctuating Demand, Volume Flexibility, Capacity Synchronization, Production Design

\section{Challenge in Planning at Fluctuating Demand}

The environment of today's modern production systems is affected by an uncertain and at the same time always changing environment [1]. The situation of variable demand and its quantities have an important role in particular. An ever increasing product variation, which leads partly to product customization, provides the flexibility of production systems with new challenges [2]. The product life cycles of modern products are also becoming shorter. In combination with the fact that the approximation of demand volumes for these products is becoming increasingly complex, production planning faces large challenges [3].

A mismatch of demand and output is determined by barely sufficient considered changes and fluctuations of demand volumes [4]. On an operational level, it leads to a poor adjustment of resources and personnel. At a strategic level, it may result in contract penalties or contract losses due to poor delivery reliability. As a result of fluctuating demand, poor capacity utilization has a negative effect on the achievement of planned economic objectives of the company in particular
[5]. For an appropriate compensation, therefore, adequate volume flexibility is needed $[6,7]$.

Volume flexibility is one of the main types of flexibility to respond to these ever increasing demand fluctuations [8] and thus one of the most important strategic instruments for the success of modern production systems. The general definition of volume flexibility corresponds to the ability to produce different output volumes profitable within a given maximum capacity of the production system [9-11]. Volume flexibility enables an adaption of the production output to the current market situation. In the short term, the velocity of volume synchronization is important; long term, it depends on the range of all possible production volumes [10]. Particularly important is the volume capacity in complex and hardly predictable demand situations [12]. In these situations, both declining demand and demand receipts have to be leveled by volume flexibility [10]. Further volume flexibility has to permit a rapid synchronization to rising demand in the initial and growth phase of a product life cycle. In the degeneration phase it enables an adaptation to the decline in sales up to the cessation of production [12].

\section{Identification of Demand-oriented Measures}

To achieve an adequate volume flexibility, operational measures are needed that can adapt the production system efficiently to changes in demand. Irrespective of the production structure, these measures are mostly applied from the field of capacity synchronization in practice. In existing production systems, this is usually carried out after completion of the production design and in the context of capacity planning, which is limited by capacity ceilings and floors [13]. Within this capacity synchronization there are different alternatives to response on demand situations. Load levelling is defined as the rapid and volume-minimal adaption of loads to a given capacity level. In turn, load adjustment approaches the capacity restrictions by shifting of entire orders. From the reverse perspective an adaption of the capacity to the load situation takes place by the capacity 
adjustment at last. In summary, it can be seen as shown in Fig. 1.

In general, capacity is defined as the performance of an economic or technical unit, of any type, size and structure, in a certain period [14]. The maximum capacity or rather the upper performance limit is determined by the allocated capacity factors personnel and equipment [15]. An employee as well as an individual machine are considered as capacities, where their temporally availability is regarded for the realization of tasks [16]. In addition to machinery and equipment that availability can be also converted to multiple used side resources, such as tools and furnishings, which support the actual production process [17]. Thus, capacity documents a fortune for economic or technical performance by using a potential formed by individual resources and personnel in a period. Increasing / reduction of work overtime or an in-house change of labour can be cited as examples as well as the operation below capacity maxima or appropriate personnel configurations [4, 18].

In the long term, however, those in small incremental progressing adjustments involve the risk to solidify existing structures and to barely consider a comprehensive reorganization of the production system in terms of the four design fields organisation, technology, logistics and personnel $[5,19]$ or to initiate appropriate measures too late [20].

A new structural linkage of existing work systems on the material flow can exemplify that. In practice, manufacturing companies often miss the moment of switching their job-shop production to a flow line system or the other way around. Moreover, volume flexibility can be increased by innovative process technologies, such as flexible machining systems. Production planning and control systems that support the production systems and processes through an information technology coupling can also bring about a dramatic improvement in the volume flexibility. In addition, the conversion and adjustment expenses and related plant equipment affects the cycle time of production. This time has a high influence on the dynamic of volume flexibility. Further, elevated inventories increase the short-term ability to adapt to volume fluctuations as well.

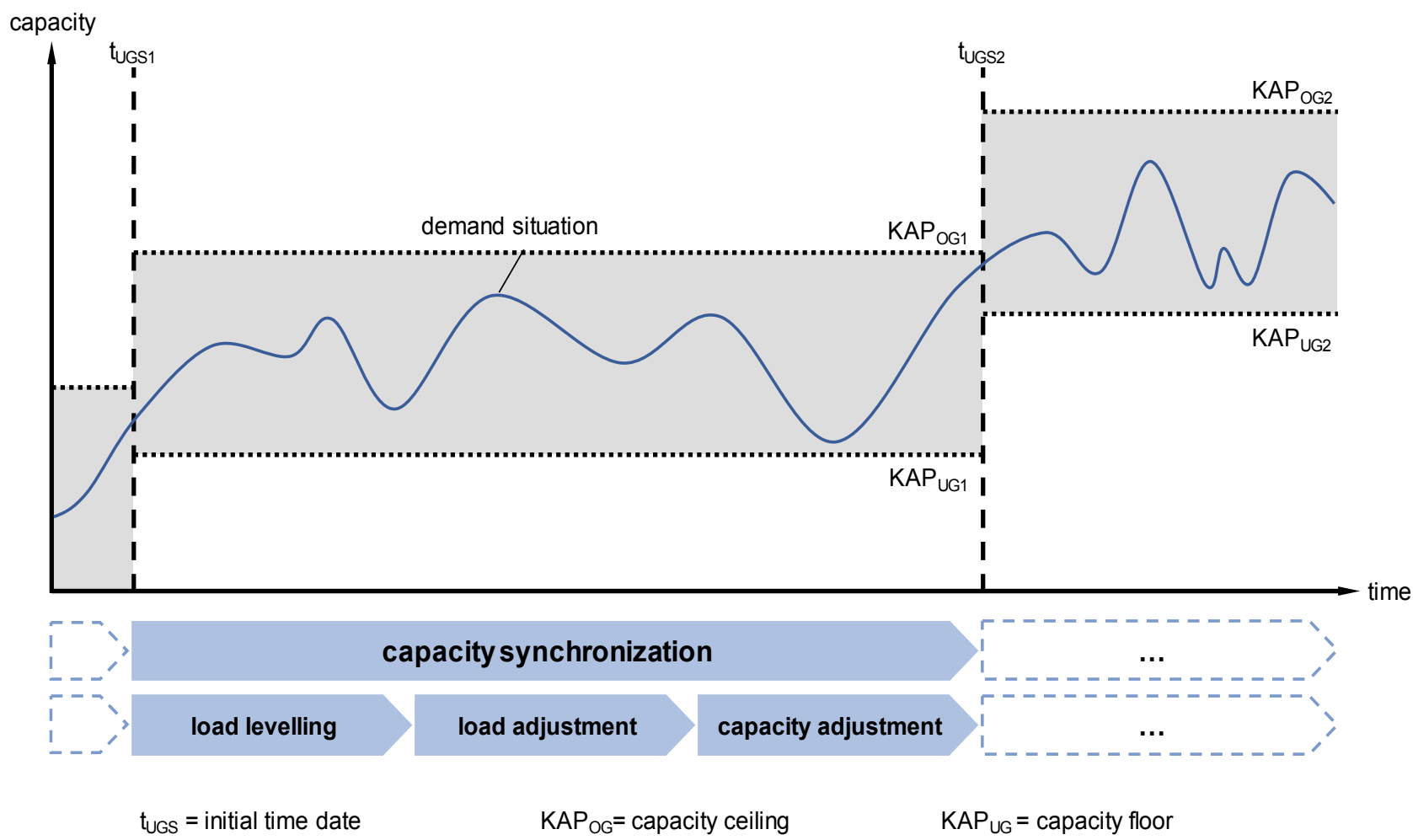

Figure 1. Capacity synchronization as response on fluctuating demand 


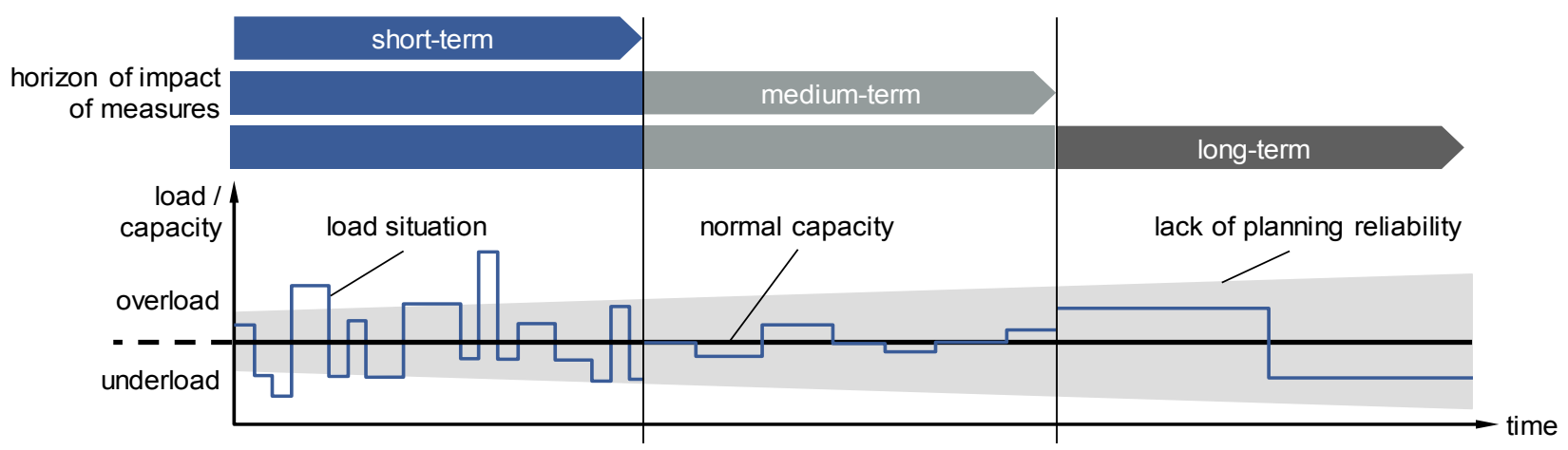

Figure 2. Impact horizon on demand fluctuations

Production design and capacity synchronization are usually considered in isolation from each other and are aimed at different corporate levels. In the context of volume flexibility required, however, a consolidation of these two planning tasks in a participative production planning is pursued. Therefore, it is necessary to consider and differentiate this time horizon each planning task and its measures focus on. Generally, the horizon can be divided into short-, medium- and long-term and has to concretize as shown in Fig. 2. In the first phase, the load caused by a given demand situation, fluctuates in a short term to the normal-capacity value. To prevent idle time or overloading, a synchronization of the load profile can be achieved by temporally shifting of operations within its buffer or by switching to other workstations. If an appropriate qualification of employees is present, flexible capacity can be also scheduled by an internal exchange. A change in quantity, schedule shifting of orders or of individual operations can lead to a temporally adjustment on capacity as well. On a technological level, individual operations can be shifted to other machines, provided that these machines have spare capacity at the required time as well as the technical requirements for processing the order.

In the second phase, the available capacity is not sufficient overall. Therefore, the capacity can be adapted to the scheduled requirements by capacity adjustment. Furthermore, the increase of overtime can be an adequate measure as well. Adaptations of machinery are also achievable for medium- but especially long-term horizons. So the remaining fluctuations can be matched as in the first phase. The third phase provides the necessity of a medium-term capacity reduction. That kind of reduction can occur by closing a second shift or decommissioning of a machine.

In general, it can be pointed out that a linkage between time horizon and each measure of capacity synchronization is quite reasonable. To plan and coordinate these measures less responsively, however, it is necessary to analyse relations between fluctuating demand volume and the resulting poor capacity situations. Thereby suitable influencing variables have to be identified that constitute an effective basis for prevention and a higher efficiency of planning. Especially small and medium-sized enterprises (SME) can benefit from those variables. Due to the fact that there are rarely independent planning departments in SME, it is difficult to plan efficient production system design and capacity synchronization simultaneously [20]. In the end the variables will be incorporated in a decision support for manufacturing SMEs.

\section{Influences on the Optimal Initial Time Date}

As seen before, a measure and its impact can be roughly assigned to a short-, medium- or long-term horizon. But to choose the appropriate measure or set of measures at the right time, it is relevant to characterise these measures concerning their influencing variables. To achieve a suitable estimate of the optimal initial time of a measure, it requires a more detailed consideration of the present load situation and the expected degree of demand fluctuation.

The situation can be described with the help of load points that occurrence forecasted at a specific time and require a distinct capacity to cope. This load points can be set in relationship via a positive or negative gradient. In relations with gradient $=O$ would cause the same load situation in the system, but at a later time date. This situation has no relevance for future consideration, since it requires no measures in terms of the present capacity and thus no redesign time. The gradient between two load points is derived from the approximate amount and duration to the possible occurrence of future demand fluctuation. Thereby, the vertical deviation of the new load point can provide information about it, whether the currently existing capacity limitation of the system is sufficient to meet the expected demand volume. Otherwise, it indicates the minimum capacity that must be obtained with the aid of a suitable measure. This relation is shown in Fig. 3. The trade between overtime and weekend shifts can exemplify that illustratively. 


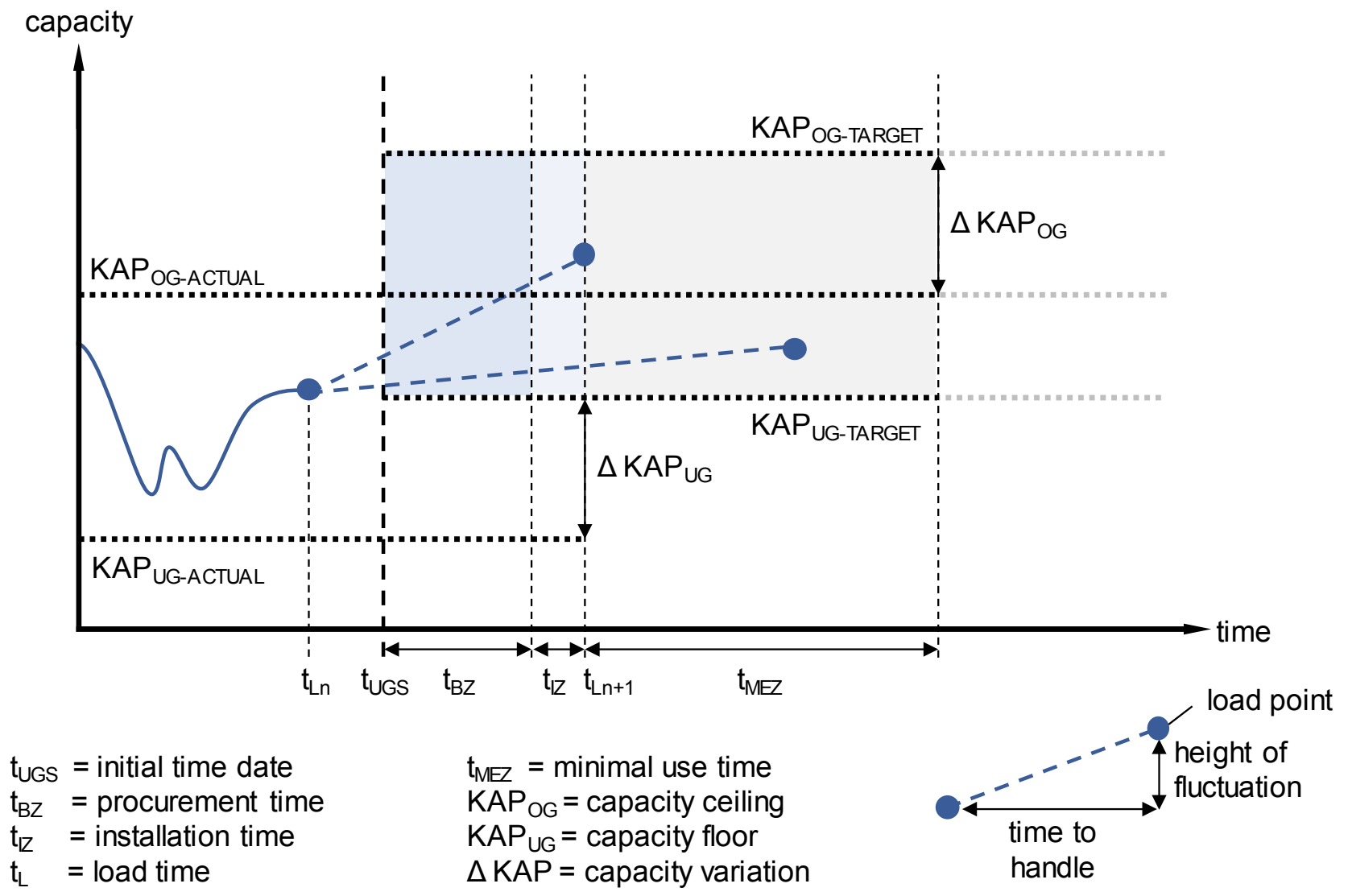

Figure 3. Influencing variables on the initial time date of measures

To identify the optimal initial time date, however, the period of time is critical to the appearance of the new load situation. Any measure can be evaluated by those response times. This response time is made up of a procurement and installation time. The procurement time is the time until the action is available, while the installation time represents the time taken until this availability is fully usable. The specific procurement time for the recruitment of other staff as well as the subsequent person-dependent learning curve can exemplify that. These variables are to be assessed for each measure. With the following equation it is possible to determinate its initial time date:

$$
t_{U G S} \leq t_{L}-t_{B Z}-t_{I Z}
$$

with $t_{U G S}=$ initial time date; $t_{L}=$ load time; $t_{B Z}=$ procurement time; $t_{I Z}=$ installation time;

$$
\mathrm{t} \in \mathbb{R}
$$

It can be stated, that the steeper is the slope between the two load points, the short-term and / or more effective it requires the use of capacitive measures. For shallow gradients, the reverse applies. Depending on this evaluation, measures can be also sorted out, which required initial time date is already in the past. These measures could be scheduled only with delay.

Another important variable, which has an influence on the selection of the appropriate measure, is the minimum use time. It describes the minimum slice of time over which a measure has to be held in order be economically viable. Experience shows that this time phase increases over the amount of additional capacity [21]. Depending on the expected additional demand volume, it means that the minimum use time corresponds to the time, it can be produced cost-covering from that on. The following equation formulates this relationship:

$$
t_{M E Z}=\frac{K_{M i}}{\left(V_{L n+1}-V_{L n}\right) \times p_{V}}
$$

with $t_{M E Z}=$ minimal use time; $K_{M i}=$ cost of measure;

$$
V_{L}=\text { demand volume; } p_{V}=\text { price per volume unit }
$$

With the help of these variables a characterization of all relevant measures of capacity planning and production design can be made. Depending on a given situation, it could be even possible to recommend appropriate combinations of measures by using a mathematical algorithm. But therefore, the specific restrictions of an applicability of each measure have to be identified in particular. For example, the number of expandable eight-hour-shifts is limited to three shifts per day. Likewise, the number of possible overtime per employee per day is fixed by law. 


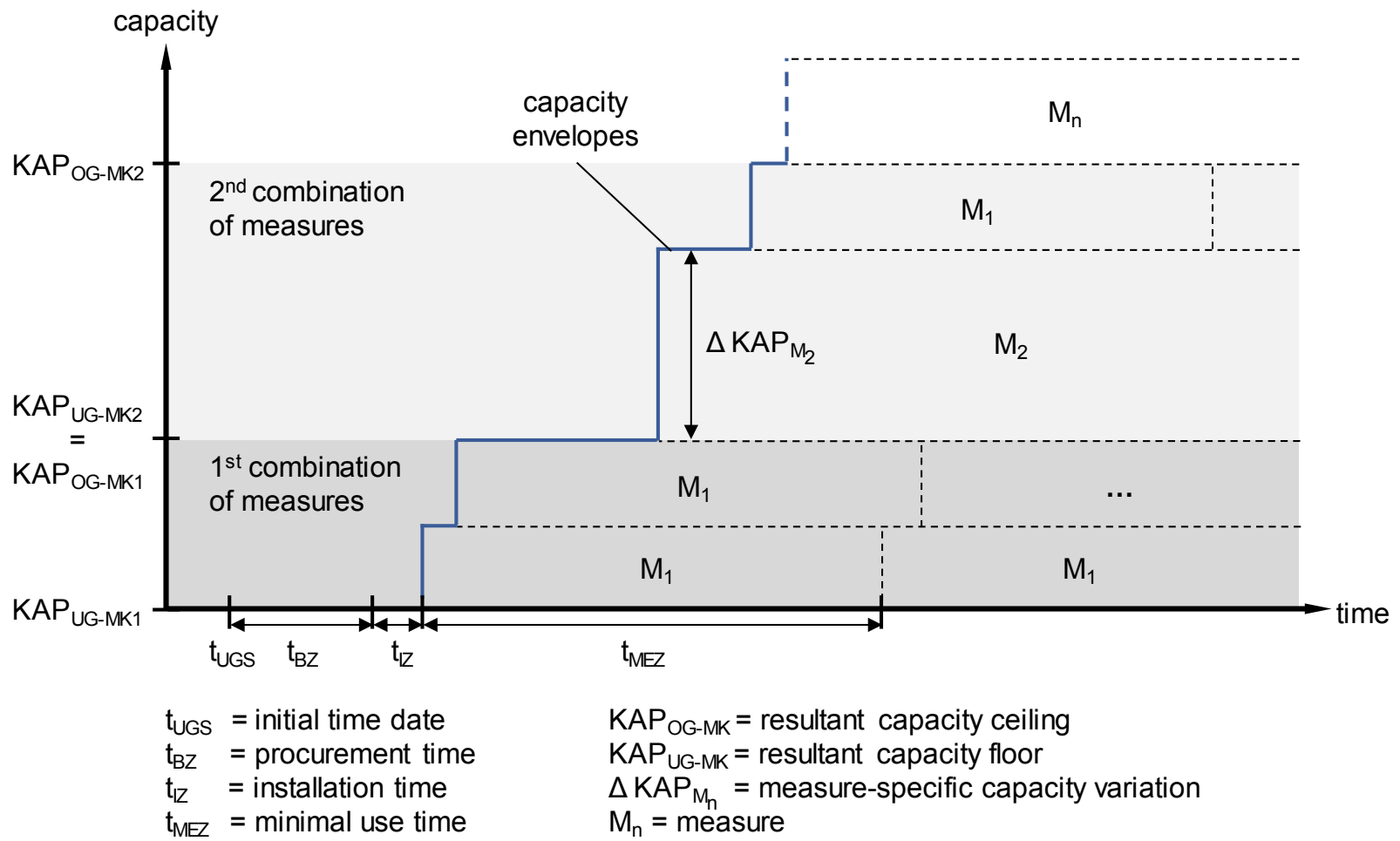

Figure 4. Dynamic capacity envelopes effected by chosen measure combinations

In turn, the purchase of new machinery and equipment is limited by available space in the plant. It is obvious that the combinations of the characterized measures must be interpreted in advance with the help of stochastics. Additionally, the ultimate use of certain measures can exclude other measures or made them available again. For example, the initialization of a second shift with more personnel hired enables more overtime of this staff. Finally, the result can be visualized in the form of so-called capacity envelopes as shown in Fig. 4. In their representation capacity envelopes serve the advantage of a pragmatic measure selection. The goal is a dynamically adaption of these envelopes to a given situation and according to each new load point as well as the measures that are already used. Finally, it provides a cost-effective adaption of operational production capacities to future capacity requirements.

\section{Conclusions}

The expected result of this research is a decision aid for the optimal design of a production system with fluctuating demand volumes. Using a classification and assessment of responding measures from capacity synchronization and production design, it enables the use of mathematical algorithms to determine the optimal initial time date for an appropriate measure to efficiently adapt to volume fluctuations of demand. Thus, by the identified response times of each measure, it is possible to influence directly to the responsiveness of a production system. In accordance with the additional consideration of the economic impact of those measures, a respective added value in terms of the required dynamic volume flexibility is provided.

Thus, the results serve a facilitating evaluation and assessment of complex combination alternatives in terms of production design and capacity planning based on production areas within the company and provides the ability to identify untapped potential for optimization. Due to the individual indication of the period, this decision aid is also for different target prospects useable: For short-term measure required as well as for longer-term planning.

\section{Acknowledgements}

The authors thank the BMWi and the AiF for the promotion of their research in the context of the research project "Decision support for manufacturing SMEs for the optimal design of the production system at fluctuating demand volumes" (GeProMe).

\section{REFERENCES}

[1] Jain, A.; Jain, P. K.; Chan, F.; Singh, S. (2013): A review on manufacturing flexibility. In: International journal of production research 51 (19), pp. 5946-5970.

[2] Parker, R. P.; Wirth, A. (1999): Manufacturing flexibility: Measures and relationships. In: European Journal of Operational Research 118 (3), pp. 429-449. 
[3] Toni, A. de; Tonchia, S. (1998): Manufacturing flexibility: A literature review. In: International journal of production research 36 (6), pp. 1587-1617.

[4] Wiendahl, H.-P. (2010): Betriebsorganisation für Ingenieure. Munich, Germany: Carl Hanser Verlag.

[5] Wagner, C. (2012): Kontinuierliche Gestaltung skalierbarer Produktionsstufen. Dissertation, Institut für Fabrikanlagen und Logistik (IFA), der Leibniz Universität Hannover. Nyhuis, P. (Hrsg.): Berichte aus dem IFA, Band 03/2012. Garbsen, Germany: PZH Verlag.

[6] Newman, W. R.; Hanna, M.; Maffei, M. J. (1993): Dealing with the Uncertainties of Manufacturing: Flexibility, Buffers and Integration. In: International Journal of Operations and Production Management 13 (1), pp. 19-34.

[7] Seebacher, G. (2013): Ansätze zur Beurteilung der produktionswirtschaftlichen Flexibilität. In: Winkler, H. (Hrsg): Anwendungsorientierte Beiträge zum industriellen Management. Berlin, Germany: Logos Verlag.

[8] Walter, M.; Sommer-Dittrich, T.; Zimmermann, J. (2011): Evaluating volume flexibility instruments by design-of-experiments methods. In: International journal of production research 49 (6), pp. 1731-1752.

[9] Bellmann, K.; Himpel, F.; Böhm, A. (2010): Messung von Flexibilität in der Produktion. Retrieved from http://link.springer.com/chapter/10.1007\%2F978-3-8349-84 01-2 11 (accessed, 19.05.2016).

[10] Sethi, A. K.; Sethi, S. P. (1990): Flexibility in manufacturing: A survey. In: The international journal of advanced manufacturing technology 2 (4), pp. 289-328.

[11] Slack, N. (1987): The Flexibility of Manufacturing Systems. In: International Journal of Operations \& Production Management 7 (4), pp. 35-45.

[12] Suarez, F. F.; Cusumano, M. A.; Fine, C. H. (1991): Flexibility and Performance: A Literature Critique and Strategic Framework. Massachusetts Institute of Technology: Sloan School.

[13] Zäh, M. F.; Moeller, N.; Vogl, W. (2005): Symbiosis of Changeable and Virtual Production. In: Zäh, M.F.E.A. (Ed) $1^{\text {st }}$ International Conference on Changeable, Agile, Reconfigurable and Virtual Production.

[14] Kern, W. (1962): Die Messung industrieller Fertigungskapazitäten und ihrer Ausnutzung. Cologne, Opladen, Germany: Westdeutscher Verlag.

[15] Nyhuis, P.; Wiendahl, H.-P. (2002): Logistische Kennlinien. Heidelberg, Germany: Springer-Verlag.

[16] REFA (1991): REFA Methodenlehre der Betriebsorganisation - Planung und Steuerung - Teil 2. Munich, Germany: Carl Hanser Verlag.

[17] Kilger, W. (1986): Industriebetriebslehre Band 1. Wiesbaden, Germany: Gabler.

[18] Nyhuis, P.; Wiendahl, H.-P. (2008): Fundamentals of Production Logistics - Theory, Tools and Applications. Heidelberg, Germany: Springer-Verlag.

[19] Nyhuis, P.; Deuse, J.; Rehwald, J. (2013): Wandlungsfähige Produktion. Heute für morgen gestalten. Garbsen, Germany: PZH Verlag.

[20] Quirico, M.; Winkens, M.; Schmidt, M. (2016): Optimale Gestaltung von Produktionssystemen bei schwankender Nachfrage, ZWF Zeitschrift für wirtschaftlichen Fabrikbetrieb Jahrg. 111 (4), pp. 204-207.

[21] Breithaupt, J.-W. (2000): Rückstandsorientierte Produktionsregelung von Fertigungsbereichen - Grundlagen und Anwendungen. Dissertation, Institut für Fabrikanlagen und Logistik (IFA), der Leibniz Universität Hannover. Düsseldorf, Germany: Fortschritt-Berichte VDI. 